\title{
Characterization of suspension poly(vinyl chloride) resins and narrow polystyrene standards by size exclusion chromatography with multiple detectors: Online right angle laser-light scattering and differential viscometric detectors
}

\author{
Jorge F.J. Coelho ${ }^{\text {a,b,*, }}$, Pedro M.F.O. Gonçalves ${ }^{\text {a }}$, Dionísio Miranda ${ }^{\text {a }}$, M.H. Gil ${ }^{\text {b }}$ \\ a Cires S.A-Companhia Industrial de Resinas Sintéticas, Apartado 20, Samouqueiro-Avanca, 3864-752 Estarreja, Portugal \\ ${ }^{\mathrm{b}}$ Chemical Engineering Department, University of Coimbra, Pólo II, Pinhal de Marrocos, 3030-290 Coimbra, Portugal
}

Received 3 August 2005; received in revised form 14 September 2005; accepted 21 September 2005

Available online 8 November 2005

\begin{abstract}
This work reports the utilization of a multi-detector size chromatography for the characterization of poly(vinyl chloride) (PVC) resins prepared by suspension polymerization in the range of temperatures between 21 and $75^{\circ} \mathrm{C}$. The chromatography equipment offers the possibility of analyzing the samples in terms of their absolute molecular mass using a combination of three detectors (TriSEC): right angle light scattering (RALLS), a differential viscometer (DV) and refractive index (RI). The PVC resins were fully characterized concerning the molecular weight distribution (MWD), its dependence with intrinsic viscosity $(\eta)$ and molecular sizes (radius of gyration, $R_{\mathrm{g}}$ and hydrodynamic radius, $R_{\mathrm{h}}$ ). Additionally, it is also presented the characterization of polystyrene narrow standards serving as reference polymers.

It is possible to find in the literature several methodologies concerning the breaking of typical aggregates presented in PVC solutions. The most suitable for the experiments were chosen, adapted and analysed by light scattering. It was observed that the application of the TriSEC to study PVC solutions was effective and it was concluded that this is an important tool for the polymer characterization, opening the possibility of running experiments avoiding the need of fractionation of the polydisperse PVC in order to obtain the Mark-Houwink-Sakurada (MHS) constants, or the utilization of MHS, that are quite diverse in literature.
\end{abstract}

(c) 2005 Elsevier Ltd. All rights reserved.

Keywords: Multi-detector size exclusion chromatography; PVC; PS

\footnotetext{
* Corresponding author. Address: Chemical Engineering Department, University of Coimbra, Pólo II, Pinhal de Marrocos, 3030-290 Coimbra, Portugal. Tel.: +351 966557206; fax: +351 239798703.

E-mail address: jcoelho3@eq.uc.pt (J.F.J. Coelho).
} 


\section{Introduction}

Among thermoplastics PVC is the second worldwide most consumed polymer in volume. This is due to its outstanding properties such as: its compatibility with many different additives, insulation properties and especially its low price. The only available industrial process for its synthesis is the conventional free-radical polymerization, which is accompanied by side reactions that changes the final polymer structure with the formation of unwanted structures known as structural defects. Apart from the undesirable effect on the polymer thermostability, it can also be expected diverse structural morphologies which will induce a different rheological behavior. One of the main characteristics of the VCM polymerization, in comparison with many other monomers, is the fact that the molecular weight is completely controlled by polymerization temperature [1]. As the temperature increases the chain transfer reaction to the monomer becomes more important preventing the chain growing, which decreases the final molecular weight. The size exclusion chromatography (SEC) with an RI detector is commonly used to determine the MWD as it is an easy and rapid technique to carry out. This methodology relies on a calibration procedure that involves the measurement of retention volumes of standards, assuming that all the polymers will elute in a similar way so that their mass distribution can be determined by reference to the calibration established with polymer standards. Unfortunately, only a few number of hompolymer standards are available commercially, being impossible their use in direct calibration. Normally, the universal calibration, suggested by Grubisic et al. [2] is used. It relates the retention volume of fraction of polymer to the hydrodynamic volume of that fraction which is given as $[\eta] M$.

The problem arises from the fact that the SEC columns do not separate the samples according to their mass, but according to their hydrodynamic volume. This approach does not consider several possibilities such as: undesirable effects between the polymer/solvent/columns and imperfect polymer dissolution which cannot be detected by using only the RI data. Furthermore, the polymer fractionation and the classical techniques to determine the MWD are troublesome and are easily affected by several sources of error. These problems are likely the main reason for so different MHS constants that can be found in literature and normally for a very limited range of molecular weights. Moreover, it is not possible to assess to any information about the accuracy and precision used in the determination. For these reasons, the universality of that equation has been questioned over the last decades. Another important requirement is related to the necessity of using diluted solutions of macromolecules for chromatography which should be fully dispersed on a molecular level, which is quite difficult to achieve even for good solvents. This problem is even more important for PVC solutions due to its tendency to form strong aggregates in solution, especially for middle/high molecular weights. The formation of clusters is more pronounced and more difficult to eliminate especially in tetrahydrofuran (THF). Stable aggregates have been detected for a long time ago and represent a critical problem to determine precisely the PVC MWD [3]. Their presence in apparently clear solutions complicates the molecular weight measurements of semicrystalline polymers. Hence, without an efficient methodology to break up these structures the results will be affected by enormous errors. After extensive investigations, Hengstenberg and Schuch [4] concluded that the amount of aggregates is related to the solvent and the method of dissolution. Other authors proposed the heating of a PVC solution in THF at $120{ }^{\circ} \mathrm{C}$ for $3 \mathrm{~h}[5,6]$ to eliminate the aggregates, followed by Abdel-Alim and Hamielec [7] that proposed the same procedure but only at $90{ }^{\circ} \mathrm{C}$ for 10 min. Pang and Rudin [8] obtained an aggregate-free PVC by heating the PVC at $120^{\circ} \mathrm{C}$ for $12 \mathrm{~h}$ in 1,2,4-trichlorobenzene (TCB), followed by the SEC measurement at $110^{\circ} \mathrm{C}$ using TCB as the mobile phase. Finally, Manabe et al. [9] proposed a methodology by using THF at room temperature, although it is necessary to predissolve the $\mathrm{PVC}$ in TCB at $130{ }^{\circ} \mathrm{C}$ for $6 \mathrm{~h}$, precipitate in methanol, filter the solution and dry it, and finally dissolve it in THF. It is obvious that the here referred methodologies presented in the literature for the preparation of PVC solutions free of aggregates are extremely severe for the polymer, due to high temperature used either to dissolve the polymer in the solvent or to set the columns temperature. Besides the practical problems, the use of high temperatures makes almost impossible to expect samples without degradation due to the low PVC thermal stability. Another important disadvantage is the difficulty to perform these procedures when it is necessary to analyze an important number of 
samples. So far, Benschop-Hendrychova [3] proposed a method which does not involve high temperatures. These authors suggested that $15 \mathrm{~min}$ of ultrasonic treatment of PVC could break up the aggregates.

The utilization of a multi-detector enable us to determine absolute molecular weights with high precision, and less sensitive to errors which normally occur in conventional SEC with RI detectors, as the change in the eluent flow [10]. In addition, it is possible to establish the relationship between the intrinsic viscosity vs molecular weight and radius of gyration vs molecular weight offering valuable information about the molecular structure. It is possible to find several examples in the literature, where the potential of these detectors arrangement is applied with success [11-13]. In this work the methodology based on ultrasonic treatment was studied and adapted. By this way it is possible to remove all the aggregates in accordance with data obtained from the light scattering detector. In industry, the molecular weight distribution of PVC is estimated from the dilute solution viscosity measurements. The results are normally expressed in terms of relative viscosity $\frac{t}{t_{0}}$, inherent viscosity $\ln \frac{t / t_{0}}{c}$ or Fikentscher $K$ value [14]. The so called " $K$ value" can be calculated from

$\ln \left(\frac{\eta}{\eta_{0}}\right)=\frac{c K}{1000}\left(\frac{75 K}{1.5 c K+1000}+1\right)$,

where $\eta, \eta_{0}$ and $c$ are the viscosity of the solvent, PVC solution viscosity and solution concentration, respectively.

The aim of this work was the identification of the most relevant structural differences between the various samples prepared in range of temperatures between 21 and $75^{\circ} \mathrm{C}$ with industrial recipes. In this way it was tried to establish the structural differences between the samples tested. This study will help us to elucidate the behavior of this polymer. In spite of its wide range of applications there is not much information related to this subject, when we compare with other commercial polymers [15]. For that purpose, the following parameters were determined: the MHS constants at 25 and $30^{\circ} \mathrm{C}$, $M_{\mathrm{z}}-\mathrm{z}$ average molecular weight, $M_{\mathrm{n}}$-number average molecular, $M_{\mathrm{w}}$-weight average molecular, $\eta$-intrinsic viscosity, $R_{\mathrm{g}}$ - gyration radius and $R_{\mathrm{h}}$ hydrodynamic radius for the different polymerization temperatures. The accuracy and precision of the results obtained from the multi-detector was examined and discussed.

\section{Experimental information}

\subsection{Materials}

The tetrahydrofuran HPLC-grade uninhibited, the sand, the alumina oxide and the PVC standard were purchased from Sigma-Aldrich. The polystyrene standards were purchased from Polymer Laboratories. The cyclohexanone was ordered from Riedel. The PVA was purchased from Syntomer. The vinyl chloride (VCM) was purchased from ShinEtsu.

\subsection{Polymerization of VCM by free radical polymerization}

The samples studied in this work were prepared by using a standard procedure applied in the PVC industry for the suspension polymerization and described in the literature [16]. Partial hydrolyzed poly(vinyl alcohol) (PVA) and hydroxyl propyl methyl celluloses were used as colloidal protectors. The only difference between each batch was the polymerization temperature. All polymerizations reactions were carried out until the critical conversion was reached. Table 1 shows the different temperatures used.

\subsection{Sample preparation for size exclusion chromatography}

One gram of PVC was totally dissolved in a dilution flask of $25 \mathrm{ml}$ over $24 \mathrm{~h}$. The solution was passed through an alumina oxide and sand column with cotton in the bottom, precipitated in water and filtered under vacuum. The polymer was then dried in the oven at $40{ }^{\circ} \mathrm{C}$ under vacuum until constant weight. Approximately $20 \mathrm{mg}$ of PVC were dissolved in $10 \mathrm{ml}$ of THF under stirring during $24 \mathrm{~h}$. The exact concentration was determined considering the weight measured and the $10 \mathrm{ml}$ of solvent

Table 1

Polymerization temperatures used for PVC preparation

\begin{tabular}{ll}
\hline Sample & Polymerization temperature $\left({ }^{\circ} \mathrm{C}\right)$ \\
\hline PVC75 & 75 \\
PVC63 & 63 \\
PVC57 & 57 \\
PVC56 & 56 \\
PVC51 & 51 \\
PVC44 & 44 \\
PVC21 & 21 \\
\hline
\end{tabular}


used (all the samples were prepared with concentrations around $2 \mathrm{mg} / \mathrm{ml}$ ). The solutions were placed in an ultrasonic bath for $1 \mathrm{~h}$, and after were allowed to stir for more $2 \mathrm{~h}$.

\subsection{Size exclusion chromatography}

The chromatography parameters of the samples were determined using a HPSEC; Viscotek (Dual detector 270, Viscotek, Houston, USA) with a differential viscometry (DV); right angle laser-light scattering (RALLS, Viscotek) and RI (Knauer K2301). The column set consisted of a PL $10 \mu \mathrm{m}$ guard column $(50 \mathrm{~mm} \times 7.5 \mathrm{~mm})$ followed by two MIXED-B PL columns $(300 \mathrm{~mm} \times 7.5 \mathrm{~mm}$, $10 \mu \mathrm{m}$ ). HPLC pump (Knauer K-1001) with a flow rate of $1 \mathrm{ml} / \mathrm{min}$. The eluent was previously filtered through a $0.2 \mu \mathrm{m}$ filter. The system was equipped with a Knauer on-line degasser. The tests were done at two different temperatures $\left(25,30^{\circ} \mathrm{C}\right)$ using an Elder $\mathrm{CH}-150$ heater. Before the injection $(100 \mu \mathrm{l})$ the samples were filtered through a PTFE membrane with $0.2 \mu \mathrm{m}$. The system was calibrated with narrow polystyrene standards. The differential refractive index $(\mathrm{d} n / \mathrm{d} c)$ used for $670 \mathrm{~nm}$ was determined as 0.105 . The analysis of light scattering data by Viscotek's software were done assuming the second virial coefficient was zero, considering the low solution concentrations used in this work.

\subsection{Calculation of intrinsic viscosity [ $\eta]$ and molecular weight $M_{w}$}

The parameters studied in this work $\left(M_{\mathrm{z}}, M_{\mathrm{w}}\right.$, $\left.M_{\mathrm{n}}, \eta, R_{\mathrm{g}}, R_{\mathrm{h}}\right)$ were calculated using the TriSEC software provided by Viscotek (version 3.0). The algorithm applied in the software is briefly described in the literature [17], and it will not be repeated here again. It also should be referred that the software monitors, the elution times of the RALLS, DV and RI detectors and adjust the volume calculation according to the RI detector.

\subsection{K-value determination}

Two PVC samples of $0.250 \pm 0.002 \mathrm{~g}$ were weighted and added to $100 \mathrm{ml}$ volumetric flasks. The flasks were filled with cyclohexanone until $2 / 3$ of the volume and carefully stirred in a temperature controlled glycerin heating bath at $85 \pm 5^{\circ} \mathrm{C}$ until complete dissolution. After that, the solutions were allowed to cool down until room temperature. The flasks were then filled completely with cyclohexanone preheated at $85 \pm 5^{\circ} \mathrm{C}$ during $90 \mathrm{~min}$, and placed in isotherm bath at $30 \pm 0.5^{\circ} \mathrm{C}$ for $20 \mathrm{~min}$. The volume of cyclohexanone was readjusted with solvent at $30 \pm 0.5^{\circ} \mathrm{C}$. The samples were then stirred until complete dissolution and filtered through a porous plaque G-1. Using an AVS 50 viscometer, the time constant for the solvent $\left(t_{0}\right)$ and the samples were determined $(t)$. To validate the sample measurements, three determinations were carried out for each sample considering that the maximum admissible difference of $0.1 \%$. The methodology described here results from the adjustment of the standard procedure DIN 53726.

\section{Theory of TriSEC operation system}

As referred above, the theory behind the calculations used with the multi-detector determinations is already described in the literature [17]. For that reason, this explanation will not be exposed here. However, it should be referred the advantages of such systems when applied to this work. In the TriSEC system, the calibration procedure is not necessary, since the molecular weight is determined directly from the light scattering data. This feature is achieved since the three detectors provided the necessary data to determine the molecular weight distribution: RALLS allows the acquisition of the polymer molecular weight across the retention volume $\left(V_{\mathrm{R}}\right)$; the DV monitor the polymer solution viscosity and the RI determines the polymer concentration.

The Viscotek's light scattering operates at a wavelength of $670 \mathrm{~nm}$ and measures the scattering at $90^{\circ}$ from incident light. A significant portion of the TriSEC software is dedicated to correct the $90-0^{\circ}$.

The excess of light scattering intensity caused by the presence of polymer molecules in the solution is directly proportional to polymer $M_{\mathrm{w}}$ and sample concentration. This relation is known as the Rayleigh equation, which relates the particle scattering function, $P(\theta)$, and the excess of Rayleigh ratio, $R_{\theta}$, to the weight-average molecular weight of the scattering polymer [18].

$\frac{K_{c}}{R_{\theta}}=\frac{1}{M_{\mathrm{w}} P(\theta)}+2 A_{2} c$,

where $c$ is the sample concentration, $A_{2}$ is the second virial coefficient, which may be assumed as zero, considering the sample concentrations used. 
$P(\theta)$, is assumed as 1 at $90^{\circ}$, therefore Eq. (2) becomes

$\frac{K_{c}}{R_{\theta}}=\frac{1}{M_{\mathrm{w}}^{\mathrm{est}}}$.

With this approach, an initial estimation of the molecular weight of each chromatographic slice can be obtained.

A Flory-Fox radius (gyration radius) is then calculated from the above $M_{\mathrm{w}}^{\text {est }}$ and the experimental measured intrinsic viscosity $[\eta]$, for linear and flexible chain molecule.

$R_{\mathrm{g}}^{\text {est }}=\frac{1}{\sqrt{6}}\left(\frac{[\eta] M_{\mathrm{w}}^{\mathrm{est}}}{\varphi}\right)^{1 / 3}$,

where $\varphi$ is the Flory viscosity constant. For each elution slice the $R_{\mathrm{g}}$ obtained from Eq. (3) is used to re-estimate $P(\theta)$ and, finally, it is determined a new estimation for $M_{\mathrm{w}}$ :

$M_{\text {New }}^{\text {est }}=\frac{M_{\mathrm{w}}^{\text {est }}}{P\left(\theta=90^{\circ}\right)}$

until the molecular weight and radius values no longer change, which normally is achieved in three iterations.

\section{Results and discussion}

The results presented in this paper were obtained at SEC column temperature of $30^{\circ} \mathrm{C}$. The MHS constants for PVC were also determined for $25^{\circ} \mathrm{C}$.

\subsection{Accuracy and precision of the equipment}

The chromatograms obtained for the different PS and PVC standards injected are shown in Fig. 1.

Polystyrene standards were used to test the accuracy and reproducibility of the results obtained from the multi-detector equipment. Using the data obtained for the different standards the calibration

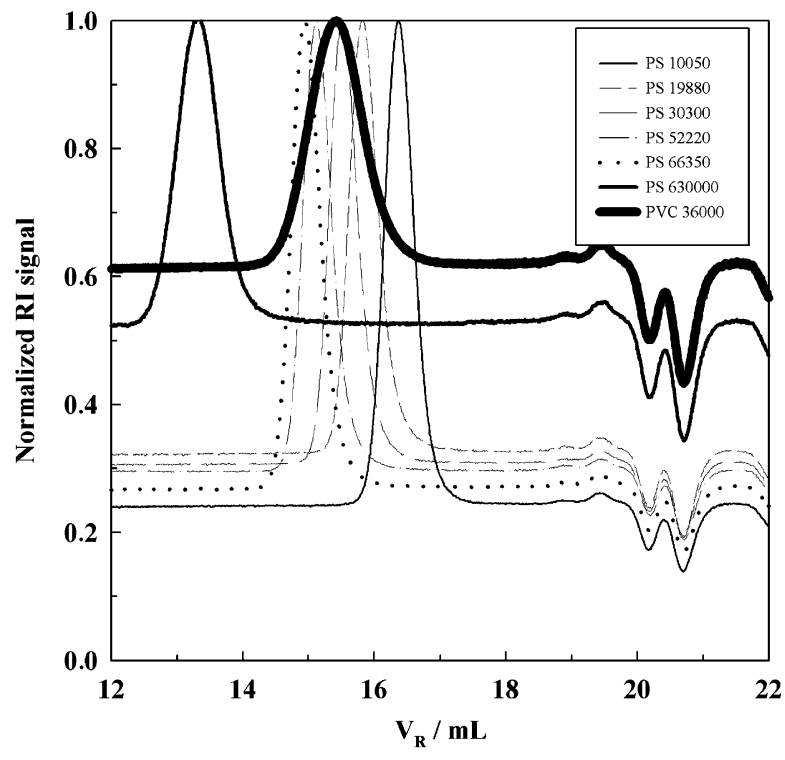

Fig. 1. RI Chromatogram for the PS standards used to create and for the calibration test with a PVC standard.

file was created based on the standard PS 66350 . The validity of such calibration was tested in the range of $M_{\mathrm{w}}$ between 10 and $630 \mathrm{k}$ with standards of PS.

Table 2 shows the results obtained for the different standards using the calibration file created here. The results shown suggest that the accuracy and precision of the equipment under these conditions is very good. Besides, in order to validate the results for PVC measurements, a PVC standard (PVC 36000) was also injected. The result present in Table 2 indicates that the calibration is also perfectly valid for the PVC just by changing the respective value of $\mathrm{d} n / \mathrm{d} c$, since the result obtained corresponds to the value presented by the supplier. The closeness between the value obtained for the PVC standard and the expected result could be achieved since the MWD is directly determined from the RALLS data, which is based on the excess scattering intensity

Table 2

Molecular weights of the standards

\begin{tabular}{|c|c|c|c|c|c|c|c|}
\hline Standard & $M_{\mathrm{w}}($ supplier $)$ & $M_{\mathrm{w}}$ (obtained) & Error $(\%)$ & $M_{\mathrm{w}} / M_{\mathrm{n}}$ & $\eta(\mathrm{dl} / \mathrm{g})$ & $R_{\mathrm{g}}(\mathrm{nm})$ & $R_{\mathrm{h}}(\mathrm{nm})$ \\
\hline PS10050 & 10050 & 10749 & 6.9 & 1.04 & 0.120 & 3.61 & 2.73 \\
\hline PS19880 & 19880 & 19519 & 1.8 & 1.03 & 0.166 & 4.84 & 3.66 \\
\hline PS30300 & 30300 & 31079 & 2.6 & 1.02 & 0.242 & 6.43 & 4.85 \\
\hline PS52220 & 52200 & 50314 & 3.6 & 1.01 & 0.346 & 8.42 & 6.65 \\
\hline PS66350 & 66350 & 65987 & 0.5 & 1.02 & 0.405 & 9.78 & 7.46 \\
\hline PS630000 & 630000 & 624111 & 0.9 & 1.01 & 2.020 & 35.24 & 27.55 \\
\hline PVC36000 & 36000 & 35313 & 1.9 & 1.20 & 0.485 & 8.30 & 6.34 \\
\hline
\end{tabular}


measured straightforwardly from the polymer molecules. The accuracy of the TriSEC equipment to determine the MHS constants relies on the direct measurements of $\eta$ and $M_{\mathrm{w}}$ directly from the detector signals, contrarily to other techniques available.

\subsection{Ultrasonic effect on polymer solution}

In this work the first target to be achieved was the establishment of a procedure which could enable the total elimination of possible clusters formed during the dissolution of PVC in THF. From the literature, the most desirable procedure found as explained before was based on the ultrasonic treatment of the PVC samples before the injection. For this preliminary study, PVC samples prepared at three different temperatures 21,53 and $75^{\circ} \mathrm{C}$ were used, which covers all range of polymerization temperature used in resin preparation.

Fig. 2 shows the chromatogram for untreated PVC (without ultrasonic treatment). In what concerns the RI chromatogram, it is not detected any small peak due to the presence of aggregates, although it is evident the presence of a bimodal distribution in the RALLS signal, which also exists on the DV signal, but not so pronounced. The first RALLS peak which appears between the retention volumes of 12 and $13.5 \mathrm{ml}$ is ascribed to supermolecular aggregates. Naturally, this peak is less intense compared to the main peak that represents the fraction without aggregates. The same information can also be observed in the relationship between the $\log M_{\mathrm{w}}$ and $V_{\mathrm{R}}$ at this region due to slope change observed. Again, the relation over $V_{\mathrm{R}} 13.6 \mathrm{ml}$ is linear, although there is an important change in the slope of the curve for retention volumes under $13.6 \mathrm{ml}$ due to the presence of aggregates. Therefore, the presence of secondary peaks at high $M_{\mathrm{w}}$ regions of the RALLS chromatograms, and the changes in the slope of the relationship log $M_{\mathrm{w}}$ and $V_{\mathrm{R}}$ at the region considered are an indication of the existence or absence of aggregates. The presence of the cluster leads to errors if the universal calibration is used to obtain macromolecular masses, whereas using a LS detector the problem is easily detected. Several procedures have been proposed to break up the aggregates of PVC in the solution. Rudin and Benschop-Hendrychova [3] proposed the utilization of ultrasonic treatment for $15 \mathrm{~min}$ with the addition of a small amount of non-ionic surfactant to prevent the degradation of PVC molecules. Other procedures based on heating the PVC solutions, for different periods of time have been proved to be effective in the aggregate dissociation. However, these methodologies are time consuming since it is necessary to heat the PVC solution at high temperatures. This approach can even be hazardous, when THF is used. Apart from the practical

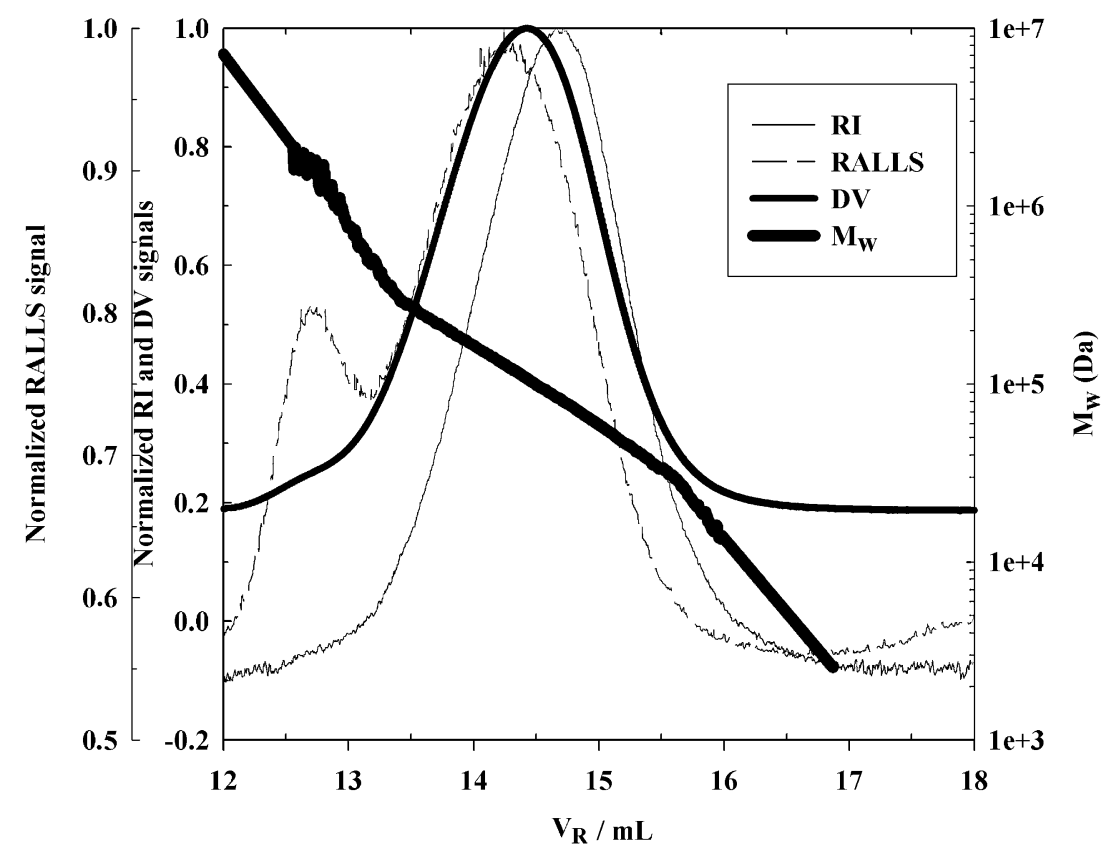

Fig. 2. Chromatograms obtained for untreated sample PVC53. 
problems, the efficiency of these methodologies was proved considering the chromatograms obtained using only data provided by RI signals.

The ultrasonic treatment was applied to the same sample analysed before for periods between 15 and $120 \mathrm{~min}$ and the respective RALLS signal was analyzed.

The superimposed RALLS chromatogram presented in Fig. 3, shows clearly that it is necessary at least one hour of ultrasonic treatment to break up all the aggregates from the solution. The presence of a small shoulder on the RALLS signal is still observed for treatment times lower than $1 \mathrm{~h}$. Contrarily, Rudin and Benschop-Hendrychova [3] have postulated that only $15 \mathrm{~min}$ of ultrasonic treatment was enough. Assuming that the conclusion from the cited authors was taken just based on RI data, they were misleading due to the lack of precision of the $\mathrm{RI}$ in the determination the presence of very small aggregates. This conclusion can be confirmed in Fig. 4 that shows evolution of the RI signal with the ultrasonic time treatment.

Analyzing Fig. 4, it can be suggested, as referred before, that it is impossible to detect the aggregate presence in the samples, based only on the RI data. It should also be stressed that no imperfection was detected in the RI chromatogram even for the sample without ultrasonic treatment. Again, the same information can be taken from the relationship between

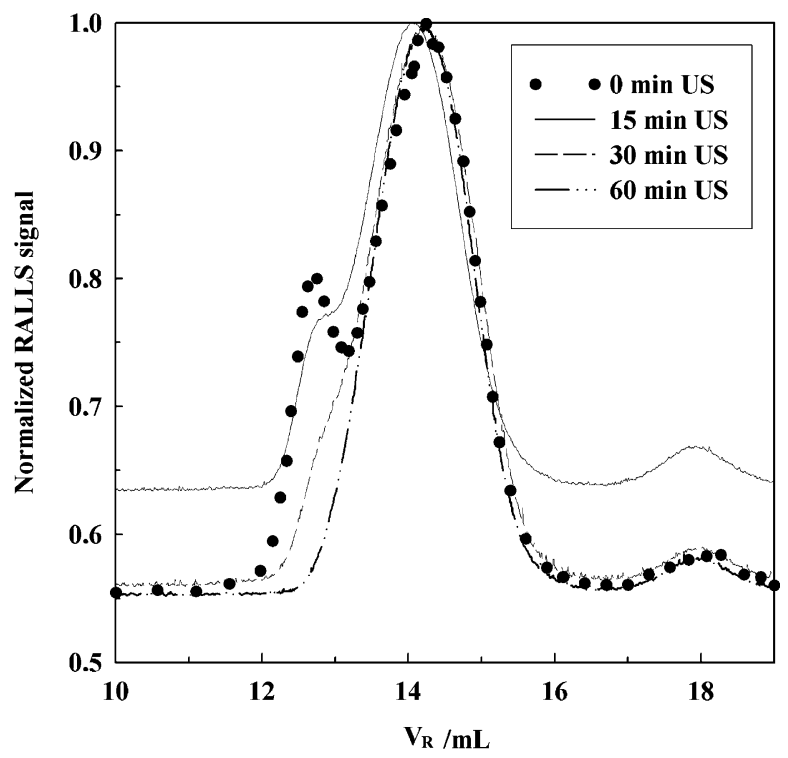

Fig. 3. RALLS chromatogram evolution with the ultrasonic time treatment for the sample PVC53.

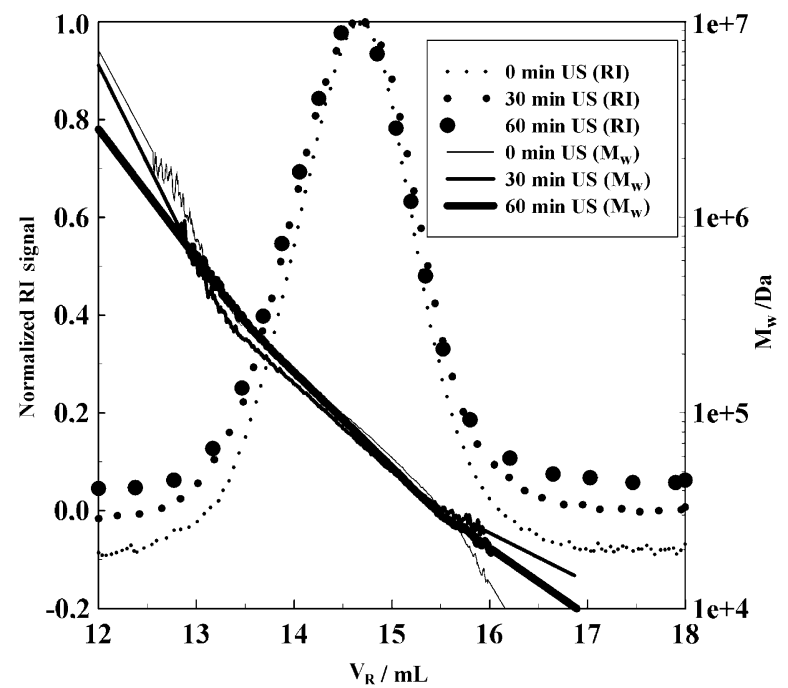

Fig. 4. RI chromatogram evolution with the ultrasonic time treatment for the sample PVC53.

$\log M_{\mathrm{w}}$ vs $V_{\mathrm{R}}$, considering that the deflection point, where curve slope changes, just disappeared for the sample after $1 \mathrm{~h}$ of ultrasonic treatment. The chromatograms obtained for $120 \mathrm{~min}$ of treatment were not shown in Figs. 4 and 5 due to the fact that the curves matched perfectly with the chromatogram obtained for $60 \mathrm{~min}$ of treatment.

The presence of aggregates leads to an increase of the RALLS intensity signal when compared to the same $\mathrm{Mw}$ of non-aggregate PVC. So it is understandable that the movement of the peak to high $V_{\mathrm{R}}$ due to elimination of aggregates decreases the $M_{\mathrm{w}}$, as demonstrated in Table 3 .

Table 3 also shows that the $\eta$ and $R_{\mathrm{h}}$ values are independent from the treatment time. However, the $M_{\mathrm{w}}$ and especially $M_{\mathrm{z}}$ values are strongly affected by the presence of aggregates. The decrease of $M_{\mathrm{w}}$ averages is ascribed to the disappearance of aggregates and not the degradation of PVC, since the $M_{\mathrm{w}}$ after $1 \mathrm{~h}$ of treatment is quite similar to the $M_{\mathrm{w}}$ after $2 \mathrm{~h}$. This feature has an outstanding importance since it shows the possibility of using an easy methodology (ultrasonic treatment) to get reliable and accurate results for the MWD of PVC, without using other strategies (e.g. heating) more difficult to implement and not feasible for a significant number of samples. Besides, any degradation motivated by the thermal instability is avoided.

This study was also carried out for other two PVC samples (PVC21 and PVC75). The final conclusions were the same. However, for the low molecular weight PVC (PVC75) only 30 min of ultrasonic 


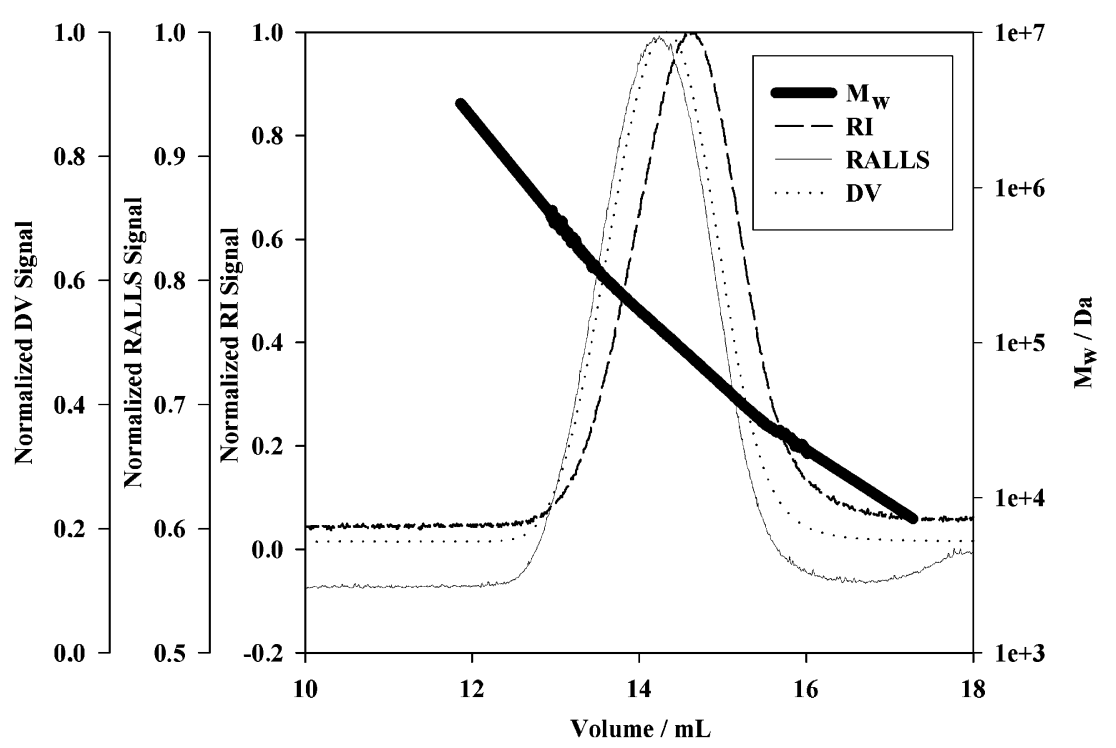

Fig. 5. TriSEC chromatograms evolution for the sample PVC53 after $1 \mathrm{~h}$ of ultrasonic treatment.

Table 3

Molecular weight averages and hydrodynamic parameters of the sample PVC53 obtained for different times of ultrasonic treatment

\begin{tabular}{lllllll}
\hline Ultrasonic time $(\mathrm{min})$ & $M_{\mathrm{n}}(\mathrm{Da})$ & $M_{\mathrm{w}}(\mathrm{Da})$ & $M_{\mathrm{z}}(\mathrm{Da})$ & $M_{\mathrm{w}} / M_{\mathrm{n}}$ & $\eta(\mathrm{dl} / \mathrm{g})$ & $R_{\mathrm{h}}(\mathrm{nm})$ \\
\hline 0 & 61195 & 213967 & $5.53 \mathrm{e} 6$ & 3.5 & 1.27 & 13.28 \\
15 & 73116 & 142642 & $1.925 \mathrm{e} 6$ & 2.0 & 1.25 & 12.83 \\
30 & 74458 & 118755 & 340698 & 1.6 & 1.25 & 12.62 \\
60 & 73830 & 108891 & 170580 & 1.5 & 1.27 & 12.50 \\
120 & 72804 & 107654 & 172000 & 1.5 & 1.26 & 12.52 \\
\hline
\end{tabular}

treatment was enough to obtain a Gaussian distribution. In order to minimize the possible differences that can be ascribed to the sample handling, all the PVC resins studied had an ultrasonic treatment during $60 \mathrm{~min}$ regardless the molecular weight that could be expected.

Fig. 5 shows the chromatograms of TriSEC for a typical PVC samples after $1 \mathrm{~h}$ of ultrasonic treatment, which are smooth, demonstrating the quality of the polymer samples and the instrument performance.

\subsection{Characterization of PVC samples}

With the problem of aggregates formation covered up, the solutions of PVC were prepared and injected according with the procedure described in Section 2.

Table 4 shows the results obtained for the different samples studied and its relation with the terminology normally used in the industry.

In the VCM polymerization the reaction temperature is extremely important due to its influence in

Table 4

Molecular weight averages, hydrodynamic parameters and $K$ value obtained for the PVC samples

\begin{tabular}{lllllllrrr}
\hline Sample & $M_{\mathrm{n}}(\mathrm{Da})$ & \multicolumn{1}{c}{$M_{\mathrm{w}}(\mathrm{Da})$} & $\mathrm{PD}$ & $\eta(\mathrm{dl} / \mathrm{g})$ & $R_{\mathrm{h}}(\mathrm{nm})$ & $R_{\mathrm{g}}(\mathrm{nm})$ & $M_{\mathrm{n}}$ theor. $^{\text {a }}$ & $M_{\mathrm{w}}$ theor. $^{\text {a }}$ & $K$ value \\
\hline PVC75 & 28204 & 60390 & 2.14 & 0.7404 & 8.268 & 10.840 & 24800 & 45800 \\
PVC63 & 37473 & 61546 & 1.64 & 0.7736 & 8.660 & 11.299 & 40000 & 70000 & 55 \\
PVC57 & 48095 & 100779 & 2.09 & 1.1262 & 11.409 & 14.909 & 50000 & 97000 & 66 \\
PVC56 & 62350 & 102847 & 1.65 & 1.1490 & 11.710 & 15.260 & 50000 & 97000 & 66 \\
PVC51 & 59286 & 116916 & 1.97 & 1.2555 & 12.510 & 16.348 & 54000 & 110000 & 72 \\
PVC44 & 91041 & 155251 & 1.70 & 1.5336 & 14.729 & 19.248 & 65000 & 140000 & 79 \\
PVC21 & 91215 & 187699 & 2.06 & 1.8390 & 16.841 & 22.007 & 155000 & 309000 & 85 \\
\hline
\end{tabular}

\footnotetext{
${ }^{a}$ Theoretical value considering the polymerization temperature used [19].
} 
the polymer properties and it is determined by the molecular weight to be produced. As expected, a decrease of the molecular weight of the samples is observed with the increasing polymerization temperature, due to the chain transfer reaction to the monomer. Moreover, it is essential to stress the concordance achieved between the $M_{\mathrm{w}}$ obtained and the values expected for the polymerization temperature used.

Concerning the polydispersity $\left(M_{\mathrm{w}} / M_{\mathrm{n}}\right)$, it was expected to obtain values around two, the small differences register in two of the samples studied can be ascribed to the purification process. Due to the fact that polymerization conducted at lower temperatures leads to very low reaction rates, typically a higher amount of initiator is used. The significant increase of the initiator may lead to a relatively higher number of chains which do not reach chain transfer stage to monomer, before critical conversion. This may explain the lower $M_{\mathrm{w}}$ of samples PVC21 than expected.

Fig. 6 shows the plot of $\log \eta$ vs $\log M_{\mathrm{w}}$ for four PVC samples (PVC75, PVC57, PVC44, PVC21) that covered the range of polymerization temperatures (or MWD) in study.

It is extremely important to refer that, regardless the molecular weight that corresponds to each PVC sample presented in Fig. 6, the region that represents the high molecular weight fraction does not show any change curve slope values close to zero.

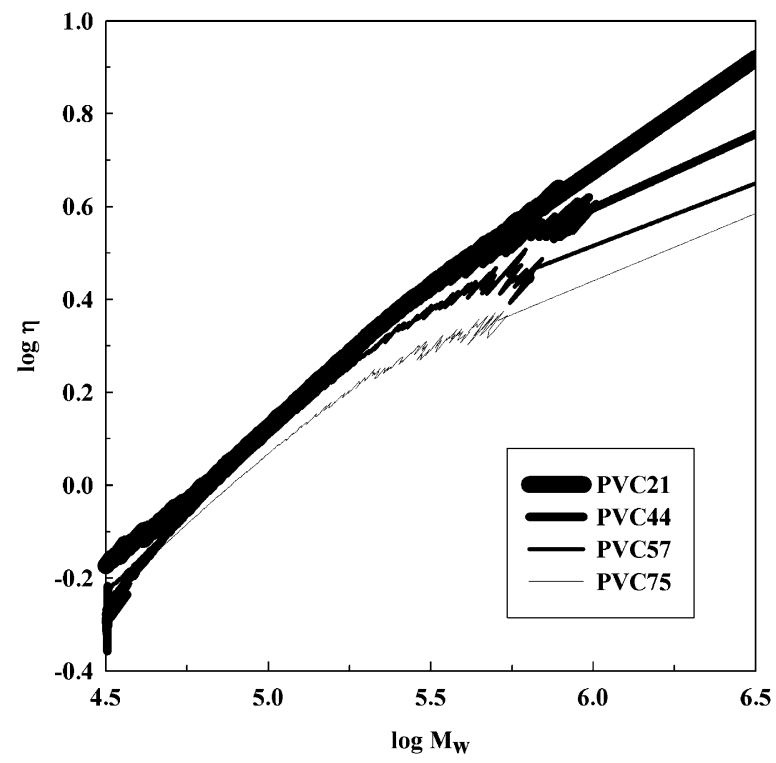

Fig. 6. Mark-Houwink-Sakurada plot for the four different PVC samples.
This observation demonstrates that the methodology used to break the aggregates was successful, indicating the quality of the results obtained. Additionally, the results of Fig. 6 show that the curves obtained for the different samples were not coincident mainly after $M_{\mathrm{w}}=10^{5.5}$ which is a direct consequence of the branching length that it is more pronounced for high reaction temperatures. It is well known that the intrinsic viscosity of branched polymer is lower than that of its linear counterpart with the same molecular weight. For low polymerization temperatures the extent of side reactions is very low leading to the formation linear PVC chains with high $\eta$ values for the same $M_{\mathrm{w}}$. Consequently, in Fig. 6 as the polymerization temperature increases the slope of $\log \eta$ vs $\log M_{\mathrm{w}}$ is less pronounced for high molecular weights. Such behavior can be justified considering that for higher temperature and same molecular weight the polymer has more branches, which results directly from the side reactions, leading to the formation of tertiary chlorines. The effect that results from these structures does not influence only the rheological behavior, but also changes the polymer thermostability, which represents an essential issue to be minimized by industry. An important work has been done relating the properties of the PVC to the MWD either based in structural analysis dealing with mechanistic features of the reaction [20] or analyzing directly the thermal behavior of PVC depending on its MWD [21]. It is well-known, that PVC thermal stability increases with the molecular weight due to lower occurrence of structural defects during the polymerization. Fig. 6 allows the same conclusion since it proves that for lower temperatures, the $\eta$ for a certain $M_{\mathrm{w}}$ is higher showing that the polymer is more linear, indicating less occurrence of side reaction during the polymerization.

The data presented in both curves (Fig. 7(a) and (b)) fit the curve perfectly, indicating the reliability of the results obtained. Moreover, the curves obtained for the two SEC temperatures studied in the PVC analysis are parallel, since the SEC separation takes place according to the size of the molecules. Basically this trend shows a uniform reduction in the molecular size with the increase in temperature.

The MHS constants obtained from Fig. 7(a) and (b) are presented in Table 5.

In Table 5 are indicated the comparison between some MHS found in the literature and the values obtained. The parameters determined for PS are in 

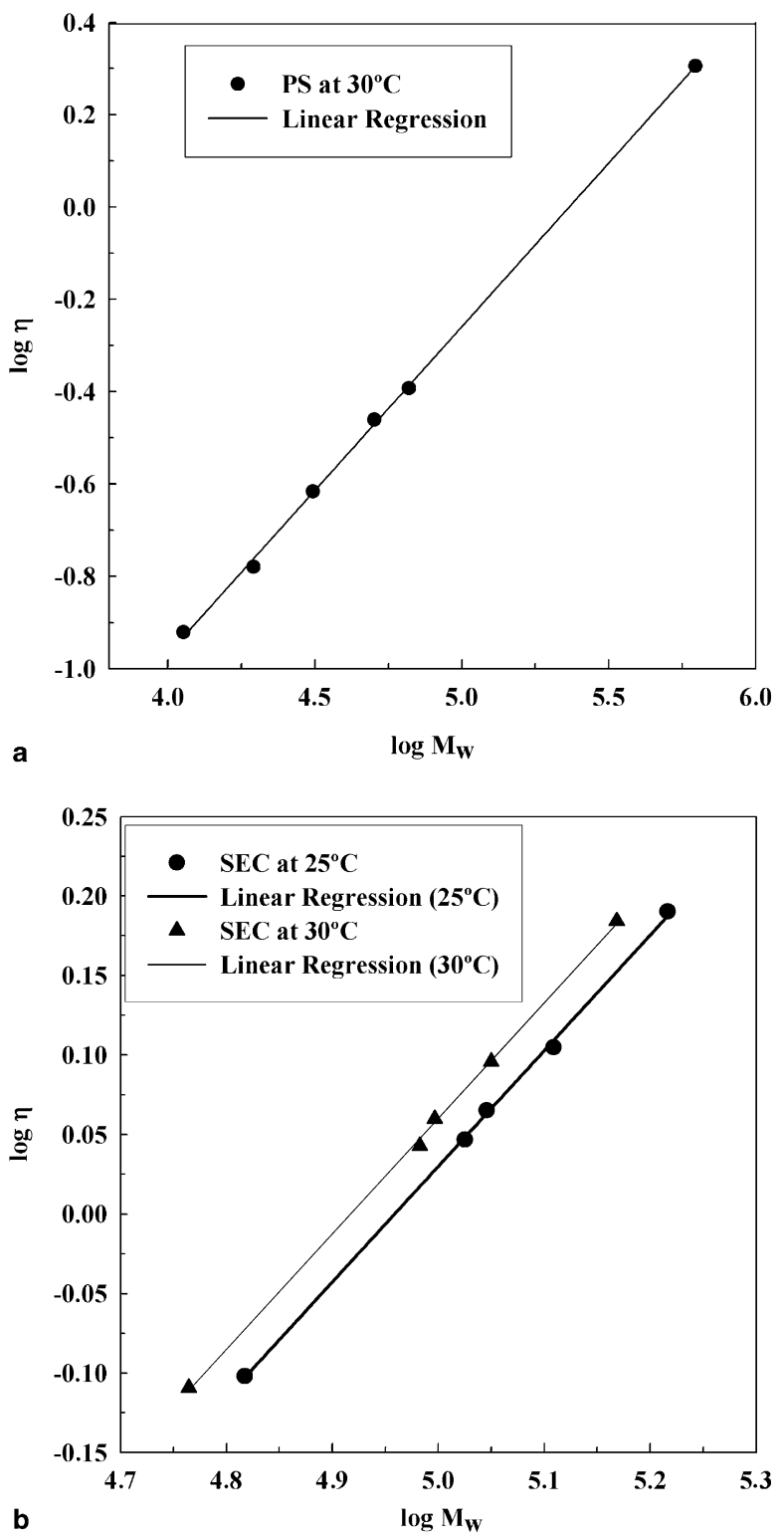

Fig. 7. Mark-Houwink-Sakurada plots, (a) PVC determined at column temperature of 25 and $30^{\circ} \mathrm{C}$, (b) PS determined at column temperature of $30^{\circ} \mathrm{C}$.

good agreement with the previously published, also determined by using a triple detector instrument. Concerning the PVC MHS constants, as referred before, these values differ largely. This can be related to the reliability of equipments used and methodologies to prepare PVC solutions free of aggregates. The good agreement obtained for the PS values, combined with the previous results shown in this work related to accuracy and precision of the TriSEC, leads to the conclusion and
Table 5

MHS constants obtained for PS and PVC

\begin{tabular}{llllll}
\hline Polymer & References & $\begin{array}{l}\text { Column } \\
\text { temperature } \\
\left({ }^{\circ} \mathrm{C}\right)\end{array}$ & $\begin{array}{l}K \times 10^{4} \\
(\mathrm{dl} / \mathrm{g})\end{array}$ & & $r^{2}$ \\
\hline PS & This work & 30 & 1.57 & 0.710 & 0.9994 \\
& Literature [13] & 30 & 1.40 & 0.70 & - \\
PVC & This work & 25 & 2.46 & 0.728 & 0.9992 \\
& Literature [22] & 25 & 1.50 & 0.77 & - \\
& Literature [22] & 25 & 1.63 & 0.766 & - \\
& Literature [22] & 25 & 4.98 & 0.69 & - \\
& This work & 30 & 2.67 & 0.727 & 0.9993 \\
& Literature [22] & 30 & 6.38 & 0.65 & - \\
& Literature [22] & 30 & 8.33 & 0.83 & - \\
& Literature [22] & 30 & 21.9 & 0.54 & - \\
\hline
\end{tabular}

the values published here should be very close to the real ones.

Regardless the algorithm used to determine MWD either by universal calibration or by light scattering, the use of a viscosimeter detector is extremely useful for the determination of the size of molecules. They can be related to the secondary structure of the polymer, either in terms of chain stiffness, conformation, or branching. Among the advantages that results from the characterization of MWD by SEC with multi detection is the possibility to determine parameters as the $R_{\mathrm{g}}$. By definition, the $R_{\mathrm{g}}$ represents the root square average of the distance of the molecular segments of the chain from its centre of gravity. The radius of gyration is used to express the molecular size and can only be determined rigorously from the initial slope of multi-angle light scattering measurements, or alternatively can be computed from the intrinsic viscosity and molecular weight via the Ptitsyn-Eizner modification of Flory-Fox equation [18].

$R_{\mathrm{g}}=\left(\frac{1}{6}\right)^{1 / 2}\left(\frac{[\eta] M}{\phi}\right)^{1 / 3}$

$\phi=2.55 \times 10^{21}\left(1-2.63 \varepsilon+2.86 \varepsilon^{2}\right)$,

where $\varepsilon=\frac{2 a-1}{3}$ and $a$ is the Mark-Houwink exponent. The latter approach is certainly non-rigorous and inaccurate for polymers molecules that deviates significantly from the flexible coil model. This is not the case either for PVC or PS. Its knowledge is useful in determining the presence and extension of chain branches and when related to the $M_{\mathrm{w}}$ is an important indication of chain stiffness. In the PVC studies, this feature is even more important, since to the best of our knowledge no data is published related to this information. In what concerns the rela- 


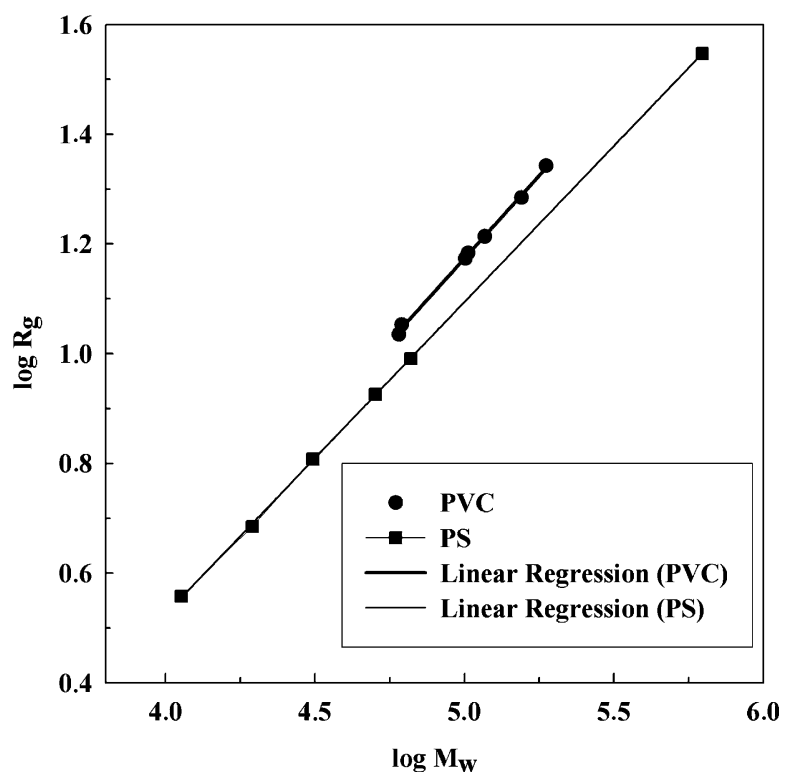

Fig. 8. Plot of $\log$ radius of gyration against $\log$ molecular weight for PS and PVC.

tions between the $R_{\mathrm{g}}$ values used to determine the branching frequencies, in the specific case of PVC the strategies developed to the preparation of a linear polymer without structural defects are only possible using living radical polymerization. These systems were recently developed [23-29] and are not yet fully established. It would be interesting to analyze these data against the values obtained for PVC prepared by traditional methodology.

The plot of $R_{\mathrm{g}}$ versus $M_{\mathrm{w}}$ shown in Fig. 8 reveals a linear relation for both polymers in the whole range of $M_{\mathrm{w}}$ analyzed, and can be described mathematically by the relation

$R_{\mathrm{g}}=K^{\prime} M^{\alpha^{\prime}}$.

The power law exponent $\alpha^{\prime}$ is related to the shape adopted by the polymer chain in solution and yields information about the polymer-solvent interactions and macromolecular conformations of the polymer. For random coil conformation it should be expected values between 0.5 and 0.6 , that start in the polymer under theta conditions $(0.5)$ to polymer in very good solvents. Rigid rod polymers typically present values for this parameter as high as one whereas spherical particles have a $\alpha^{\prime}$ equal to $1 / 3$ [30].

The data presented in Table 6 allows us, in first instance, to compare the obtained values with the literature data. Even for the PS it is relatively difficult since they can differ widely from different values published [31]. The obtained values confirm that PS and PVC adopt a conformation known as random coil, since the $R_{\mathrm{g}}$ is roughly proportional to the square of molecular weight, as expected for synthetic polymers in dilute solutions. These materials can display large number of possible conformations with different energies, although the differences are small enough to allow changes from one conformation to another. This feature gives a big flexibility to the macromolecules in solution. For a specific system polymer/solvent it is predictable that the value of $\alpha^{\prime}$ does not change significantly with the MWD. In addition, the $\alpha^{\prime}$ obtained for PS shows that chains are in random coil conformation and expanded due to the excluded volume effect since the THF is a very good solvent for this polymer, as reported in literature [30]. The relationship between $R_{\mathrm{g}}$ and $M_{\mathrm{w}}$ for the polystyrene shown in Fig. 8 agreed perfectly well with the data obtained by Huang et al. [13]. In what concerns the PVC no information was found in literature.

The quality that could be expected from a detector based on the light scattering was assumed to be reliable just when $R_{\mathrm{g}}$ of the molecule was larger than $10 \mathrm{~nm}$. The results presented in this work prove that by using the conjunction of these three detectors it is possible to determine, with high levels of accuracy and precision, even small values of $R_{\mathrm{g}}$, since the comparison of the available data in the literature for typical values of $R_{\mathrm{g}}$ of PS shows an important match and the correlation coefficient obtained for the relation $R_{\mathrm{g}}=K^{\prime} M^{\alpha^{\prime}}$ shows a value that can be considered one, which basically means that when the data obtained for small $R_{\mathrm{g}}$ values the adjustment continues to be perfect. The possibility of measuring polymers whose effective hydrodynamic radius is smaller that $10 \mathrm{~nm}$ is assured also by high viscometer

Table 6

Radius of gyration scaling coefficients for PS and PVC

\begin{tabular}{|c|c|c|c|c|c|c|}
\hline \multirow[t]{2}{*}{ Polymer } & \multicolumn{3}{|c|}{ Polystyrene } & \multicolumn{3}{|c|}{ Poly(vinyl chloride) } \\
\hline & $K^{\prime}$ & $\alpha^{\prime}$ & $r^{2}$ & $K^{\prime}$ & $\alpha^{\prime}$ & $r^{2}$ \\
\hline Obtained & 1.77 & 0.569 & 0.9999 & 1.42 & 0.604 & 0.9982 \\
\hline Literature [13] & 1.80 & 0.564 & - & - & - & - \\
\hline
\end{tabular}




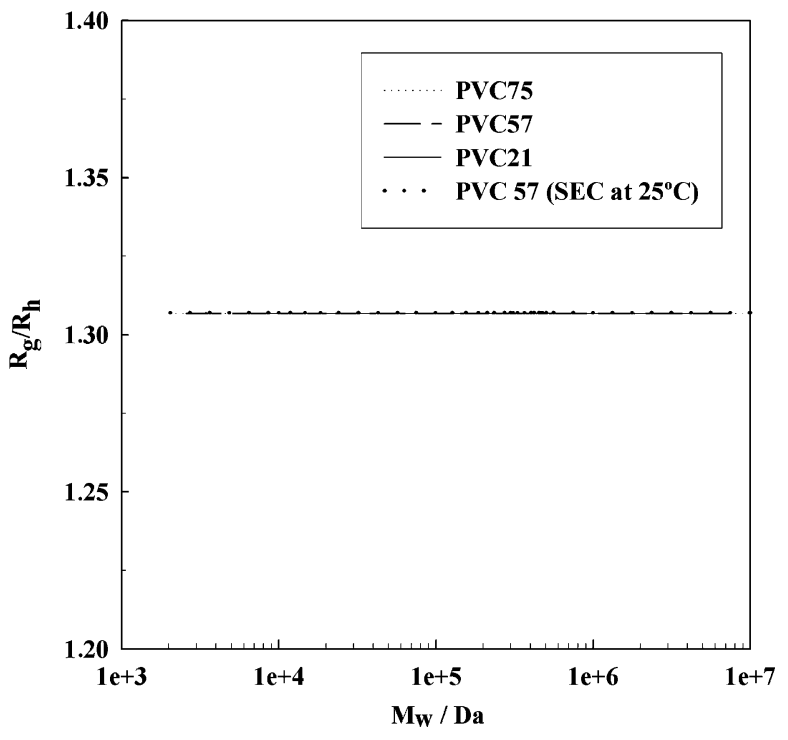

Fig. 9. $R_{\mathrm{g}} / R_{\mathrm{h}}$ ratio dependence with the $M_{\mathrm{w}}$ for 3 PVC samples polymerized at different temperatures.

precision. Its capacity to determine $R_{\mathrm{g}}$ values as low as $1 \mathrm{~nm}$, which is equivalent of $10 \AA$, a value close to the chemical bond dimension is extremely important in the polymer characterization field. The ration $R_{\mathrm{g}} /$ $R_{\mathrm{h}}$ dependence with $M_{\mathrm{w}}$ reflects the architecture and conformation of the polymers in solution and can be conveniently obtained for each fraction eluting by this TriSEC technique.

Fig. 9 shows that the ratio $R_{\mathrm{g}} / R_{\mathrm{h}}$ is constant over the entire range of molecular weight, regardless the conditions used, and has a value close to 1.3 which indicates a random coil conformation, confirming again the conclusion taken before. The constant value obtained allows also to conclude that the PVC chains adopt the same conformation in solution regardless the polymerization temperature (in the range between 21 and $75^{\circ} \mathrm{C}$ ), the molecular weight considered and the solution temperature (in this case THF at 25 and $30^{\circ} \mathrm{C}$ ). The results presented in Fig. 9 shows that THF is a good solvent due to the ratio values obtained, otherwise the PVC and PS chains would assume a compact structure resulting in a lower $R_{\mathrm{g}} / R_{\mathrm{h}}$.

The value $\left(R_{\mathrm{g}}^{2} / M_{\mathrm{w}}\right)^{1 / 2}[32]$ is frequently used as reference to the chain stiffness. The importance of this quantity relies on their relation to physical and mechanical behavior, allowing the direct comparison between different materials. The melt and solution viscosity depend directly on the radius of gyration of the polymer and on the chain's capability of being deformed. It is extremely common to be

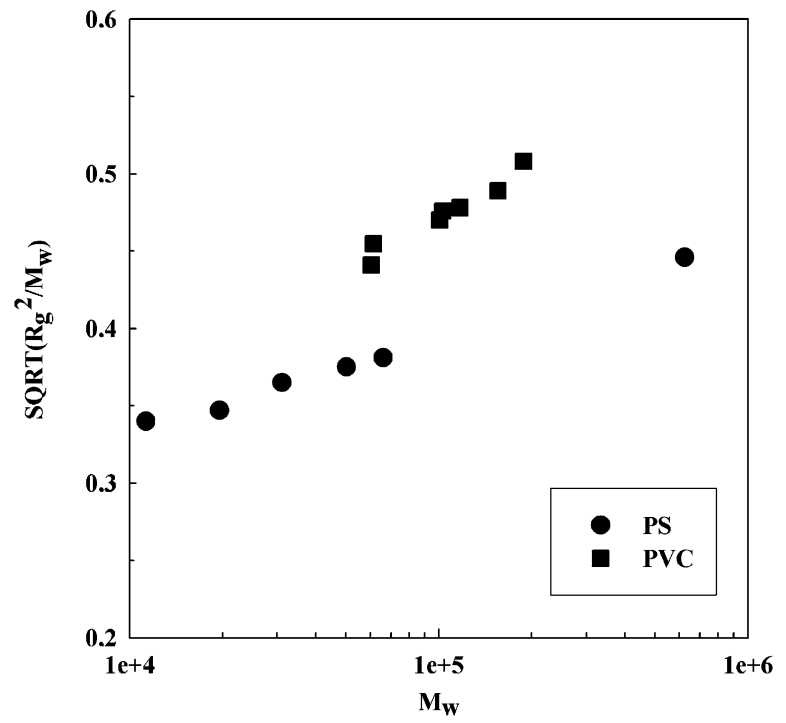

Fig. 10. Evolution of the chain stiffness with the $M_{\mathrm{w}}$ for the PS and commercial PVC.

faced with conflicting requirements due to opposite needs of maximization of the material performance. It is more convenient to use high molecular weight polymer to obtained good physical properties and in the specific case of PVC good thermal behavior. On the other hand, low molecular weights allows the polymer processing under mild conditions, such as the melt viscosity. This is the reason why typical molecular weight range of PVC is between 60000 and $90000 \mathrm{~g} / \mathrm{mol}$. Besides the possibility to compare the mechanical and physical performance, the quantity $\left(R_{\mathrm{g}}^{2} / M_{\mathrm{w}}\right)^{1 / 2}$ is an important factor to be considered in the polymerization kinetics. The main reason is the fact that the bimolecular termination process incorporates translational and diffusion of polymer chains during the radical polymerization [33]. These movements can be prevented when the mobility is lower due to the stiffness of the polymer main chain.

The comparison between the values presented in Fig. 10 for PS and PVC allow concluding that for the same $M_{\mathrm{w}}$ the PVC chains are stiffer than PS chains. In both cases, as expected the stiffness chain increased with the $M_{\mathrm{w}}$.

\section{Conclusions}

The multi-detector SEC chromatography represents an easy and rapid methodology for the determination of the constants $k$ and $\alpha$ of the MHS equation, with the possibility of relating the intrinsic viscosity with molecular weight. Among the advan- 
tages related to the precision and accuracy of the results discussed in this work, the possibility to determine the MHS constants without using the standard procedures that normally can take weeks to complete is an outstanding advantage of this system. This technique proved also to be convenient for the study of the shape and conformation of polymer without the need to use tedious and time consuming methodologies.

The claim that an absolute $M_{\mathrm{w}}$ is measured using the LS detector is entirely true in the sense that an absolute Rayleigh scattering ratio is measured by comparison between the polymer sample and the scattering response obtained from the pure substance, whose Rayleigh ratio is known. This feature was demonstrated by the high level of accuracy obtained for the MWD of a PVC standard against a calibration made with a PS standard. The presence of aggregates in the PVC solution was identified and eliminated using a methodology published in the literature based on ultrasonic treatment. The methodology proved to work when it is used at least $60 \mathrm{~min}$ of ultrasonic treatment, considering the RALLS data chromatogram. The MHS were determined for PS at $30{ }^{\circ} \mathrm{C}$ and for PVC at 25 and $30^{\circ} \mathrm{C}$.

The use of TriSEC for the polymer characterization showed results with high level of precision and accuracy. It is a technique that should always be considered, especially for polymers such as the PVC without commercial available standards.

\section{Acknowledgement}

The authors gratefully acknowledge Eng. Rui Soares (Paralab) for the valuable scientific discussion and technical support providing all the conditions to work with Viscotek equipment.

\section{References}

[1] Nass LI. Encyclopedia of PVC, vol. 1. New York and Basel: Marcel Dekker Inc; 1992.

[2] Grubisic Z, Rempp P, Benoit HJ. Polym Sci B 1967;5:753.

[3] Rudin A, Benschop-Hendrychova IJ. Appl Polym Sci 1971; 9:2881.

[4] Hengstenberg J, Schuch E. Makromol Chem 1964;74:55.
[5] Lyngaae-Jorgensen JJ. Chromatogr Sci 1971;9:381.

[6] Chan RK, Worman C. Polym Eng Sci 1972;12:437.

[7] Abdel-Alim AH, Hamielec AE. J Appl Polym Sci 1972;16: 1093.

[8] Pang S, Rudin AJ. Appl Polym Sci 1993;49:1189.

[9] Manabe N, Kawamura K, Toyoda T, Ishikawa M, Mori SJ. Appl Polym Sci 1998;68:1801.

[10] Morey TH, Coll H. J Appl Polym Sci 1995;56:65.

[11] Huang Y, Lujia B, Lewei B, Dezhen S, Chengwei S, Zhongde X, et al. Polym Bull 2000;44:539.

[12] Huang Y, Xu Z, Ma D, Yang J, Mays JW. Int J Polym Anal Charact 2003;8:383.

[13] Huang Y, Peng H, Lam JWY, Xu Z, Leung FSM, Mays JW, et al. Polymer 2004;45:4811.

[14] Fikentscher HJ. Cellulosechemie 1932;13:58.

[15] Kawauchi T, Isshiki M, Takeda M, Shibayama M. Polymer 2001;42:3875.

[16] Butters G. Particulate nature of PVC: formation, structure, and processing. London: Applied Science Publishers; 1982.

[17] Beer MU, Wood PJ, Weisz J. Carbohydr Polym 1999;39:377.

[18] TriSEC GPC Software Manual. Ver. 3. Houston: Viscotek Corp.; 1996, p. A2-18.

[19] Salamone J, editor. Polymeric materials encyclopedia, vol. 9, 1996.

[20] Starnes WHJ. Prog Polym Sci 2002;27:2133.

[21] Kamal IM, Adam GA, Getta HK. Thermochim Acta 1983; 62:355.

[22] Braundrup J, Immergut EH, Grulke EA, editorsPolymer handbook. 4th ed. New York: Wiley; 1999.

[23] Percec V, Ramirez-Castilho E, Hinojosa-Falcon LA, Popov AV. J Polym Sci Part A: Polym Chem 2005;43:2276.

[24] Percec V, Popov AV, Ramirez-Castilho E, Hinojosa-Falcon LA. J Polym Sci Part A: Polym Chem 2005;43:2185.

[25] Percec V, Popov AV, Ramirez-Castilho E, Coelho JFJ, Hinojosa-Falcon LA. J Polym Sci Part A: Polym Chem 2005;43:788.

[26] Percec V, Popov AV, Ramirez-Castilho E, Coelho JFJ. J Polym Sci Part A: Polym Chem 2005;43:778.

[27] Percec V, Popov AV, Ramirez-Castilho E. J Polym Sci Part A: Polym Chem 2005;43:295.

[28] Percec V, Popov AV, Ramirez-Castilho E, Coelho JFJ, Hinojosa-Falcon LA. J Polym Sci Part A: Polym Chem 2004;42:6364.

[29] Percec V, Popov AV, Ramirez-Castilho E, Coelho JFJ, Hinojosa-Falcon LA. J Polym Sci Part A: Polym Chem 2004;42:6267.

[30] Teresa M, Laguna R, Medrano R, Plana MP, Tarazona MP. J Chromatogr A 2001;919:13.

[31] Fetters LJ, Hadjichristidism N, Linder JS, Mays JW. J Phys Chem Ref Data 1994;23:619.

[32] Sperling LH. Introduction to physical polymer science. New York: John Wiley \& Sons; 1992.

[33] Matsumoto A, Nakagawa E. Eur Polym J 1999;35:2107. 